\title{
Implementation of a Differentiated Approach to the Organization of Distance Learning
}

\section{Implementación de un enfoque diferenciado a la organización del aprendizaje a distancia}

\author{
Dmitry V. Kachalov \\ Ural State University of Railway Transport, Russia \\ ORCID: https://orcid.org/0000-0003-1013-9850 \\ Oksana N. Ivanova \\ Yakut State Agricultural Academy, Russia \\ ORCID: https://orcid.org/0000-0002-4122-9333

\section{Nina V. Gubanova*} \\ Ulyanovsk State Agrarian University named after P.A. Stolypin, Russia \\ ORCID: https://orcid.org/0000-0003-4662-7338 \\ Nadezhda V. Belotserkovskaya \\ North-Eastern Federal University named after M. K. Ammosov, Russia \\ ORCID: https://orcid.org/0000-0003-2648-4966

\section{Sergey V. Kuznetsov} \\ Kazan Federal University (Naberezhnye Chelny Institute), Russia \\ ORCID: https://orcid.org/0000-0003-3971-9445
}

Received 01-14-20 Revised 03-03-20 Accepted 05-23-20 On line 06-12-20

*Correspondencia

Email: aigoul@rambler.ru
Citar como:

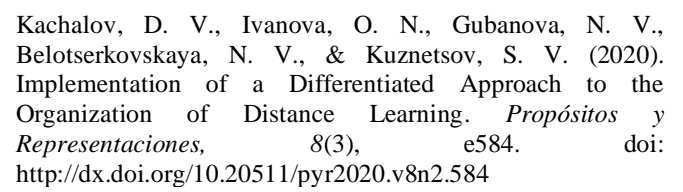

http://dx.doi.org/10.20511/pyr2020.v8n2.584 


\section{Summary}

The widespread practice and results of the introduction of distance learning in several countries prove its economic efficiency. In this article, the authors consider the possibilities and advantages of using a differentiated approach in the practice of distance learning at a university. The article describes the pedagogical experience of structuring distance learning in the form of a new educational model - a block-modular system used by teachers in the practice of higher education. The authors argue that such structuring ensures the integrity of the perception and presentation of educational material, contributes to a better mastery of the discipline, provides the ability to build personal educational trajectories of students and identifies the following principles: flexibility, individualization, modularity, differentiated form of control..

Keywords: Differentiation; Approach; Modularity; Block; Distance Learning.

\section{Resumen}

La práctica generalizada y los resultados de la introducción del aprendizaje a distancia en varios países demuestran su eficiencia económica. En este artículo, los autores consideran las posibilidades y ventajas de utilizar un enfoque diferenciado en la práctica del aprendizaje a distancia en una universidad. El artículo describe la experiencia pedagógica de estructurar el aprendizaje a distancia en forma de un nuevo modelo educativo: un sistema modular de bloques utilizado por los docentes en la práctica de la educación superior. Los autores sostienen que dicha estructuración garantiza la integridad de la percepción y la presentación del material educativo, contribuye a un mejor dominio de la disciplina, proporciona la capacidad de construir trayectorias educativas personales de los estudiantes e identifica los siguientes principios: flexibilidad, individualización, modularidad, diferenciación forma de control.

Palabras clave: Diferenciación; Enfoque; Modularidad; Bloque; Aprendizaje a distancia

\section{Introducción}

In Russian higher education, distance learning is quite innovative and goes through the adaptation phase, accompanied by widespread practice and training. At the moment, in Russia there is a process of intensive development of a single educational space based on constantly improving information, communication and technological tools. All teachers from junior level to the faculty are at the stage of active training.

It should be noted that the sphere of education has changed significantly lately as a result of new information technologies that allow organizing the educational process to a new level in the framework of training and perception.

The widespread practice and results of the introduction of distance learning in several countries prove its economic efficiency. The analysis of organizational forms of distance learning showed that it gained the greatest popularity.

Currently, in the face of a serious financial crisis, this form of training is relevant, especially in the coordinates of corporate training. In the conditions of the economic crisis, training should be aimed at achieving two main goals - minimizing the risks associated with personnel and increasing the efficiency of activities. Distance learning is a real alternative to full-time advanced training, besides the most effective according to the criterion of financial and time costs.

On the other hand, critics of distance learning say that its quality cannot even be compared with distance learning, and such teaching technologies only allow you to finish school 
with minimal investment of effort and resources without gaining actual knowledge. The low quality of distance learning, according to some experts, can be explained by the lack of highquality methods of distance learning, the average quality of electronic courses and the most elearning environments. In addition to the low quality of knowledge, opponents of distance learning note that this is not an education for all student groups, linking this with the need for constant self-control and self-discipline of students in the learning process. At the same time, the lack of direct communication between the teacher and excludes the ability to train the student's personality, distantly transmitted knowledge lose their emotional coloring, reducing the level of students' interest in learning.

Information technology is not only a tool that allows you to expand the amount of information, methods of its transmission and processing with traditional forms of training, but also a real opportunity to form new educational models. New forms of education are becoming objective. At the modern level, with the help of education, a new mentality is formed, new social relations are formed, new social relationships are generated.

Distance learning is characterized by the global educational environment, accessibility for all segments of the population.

At the modern level, any result is important as a result of training. The distance learning system - as innovative learning, is based mainly on students independently obtaining the necessary volume and the required quality of knowledge at the same time involves the use of a wide range of traditional and new information technologies.

All of the above determines the relevance of further studies of the development of distance learning in the modernization and reality of the information age, as well as the need to develop innovative models of distance learning for higher education, taking into account the opportunities and risks of the global expansion of the global educational space.

\section{Method}

\section{Distance learning is the subject of many works by scientists and educators}

oeva, N. I. writes that the choice of pedagogical technologies is always determined by the concept of training used, which depends on the final goal set, achieving which the student will have the necessary knowledge in his specialty, i.e. Remote Circuiting is not suitable for all specialties (Boeva, 2006).

On the positive side, this training is also characterized by Yu.V. Sakulina and defines it as a distance learning system only in combination with the latest information technologies, communication technologies, and internetization (Sakulina, 2018). The use of information and communication technologies in the implementation of distance education.

Saenko, L. A. uncovers the potential of distance learning in modern conditions development of a vocational education system (Saenko, 2015). Galyaev, V.S., \& Hasanova, Z.A. consider and analyze the most famous classifications of models distance learning. They proposed a classification based on several signs, an analysis of the options for organizing distance learning was carried out (Galyaev \& Hasanova, 2012).

Celebird, I.N., Lesnaya, N.S., \& Repka, V. B. in their work proposed a multi-agent ontological approach to creating distributed distance learning systems (LMS), which is based on the principles of the Semantic Web project and agent technologies (Celebird et al, 2004).

Dubrovskaya, Yu. A. points out the special role of the teacher in this system, notes the increased importance of self-education is also determined by the tendency of becoming a new education 
system, according to which the teacher tutor performs more functions of the developer of educational programs, the organizer of an independent (Dubrovskaya, 2005).

Shevelev, N.A., \& Kuznetsova, T.A. share their pedagogical experience in conducting classes at the PDF, which uses the MOODLE (Modular Object-Oriented Dynamic Learning Environment), which is a package software for creating distance learning courses and web sites (Shevelev, \& Kuznetsova, 2011).

Skripkina, Yu.V. points to the negative side of distance learning: lack of communication and reveals the principles of distance creative self-realization of students (Skripkina, 2012).

From the above analysis of the work of teachers, it is clear that not all aspects of distance education are fully studied, the understanding of individual tasks is often debatable in nature, in their practical solution a particular didactic orientation is observed, which requires further elaboration. The purpose of our study is to analyze the organizational part of distance learning, the possibility of building personal educational trajectories of students, i.e. to consider the possibilities and advantages of applying a differentiated approach in training.

\section{Resultados}

Differentiation is such a training system in which each student, mastering some minimum of general education, gets the right to pay attention to those areas that are most suited to his inclinations. Differentiated education, according to the encyclopedia, is "the separation of curricula and programs in high school"

Differentiation (from Latin differentia - difference) means the dismemberment, division, stratification of the whole into parts, forms. As for the differentiation of the educational process, this is an action whose task is to separate students in the learning process in order to achieve the main goal of training and to take into account the characteristics of each student. From a social point of view, the goal of differentiating education is to form the creative, intellectual, professional potential of society in order to rationally use the capabilities of each member of the society in its relations with society. From the didactic point of view, the goal of differentiation is to solve the problems of education by creating a new didactic system of differentiated teaching of students based on a fundamentally new motivational basis. From the psychological and pedagogical point of view, the ultimate goal of differentiation is its individualization, based on creating optimal conditions for identifying inclinations, developing the interests and abilities of each student. Having considered the concept of "differentiation of education," one cannot help but touch upon the following concept, "differentiated approach." In pedagogical literature, the discussion of a differentiated approach is often associated with differentiation of education.

For example, Antonova, M. L. Defines the differentiation of education as a way of organizing the educational process, in which individually typological characteristics of the personality are taken into account (Antonova, 2017).

A differentiated approach is determined by the pedagogical intuition of the teacher in connection with the implementation of the principle of individualization of education. E.S.Rabunsky argues that a differentiated approach to learning is determined, first of all, as a pedagogical an approach that takes into account the features of individual ... didactic conditions (Rabunsky, 1975).

If we are talking about a differentiated approach, then we are talking about technology of an individual approach to students in order to determine the level of their abilities and capabilities, their training at all stages of training. The application of a differentiated approach in training involves the training of different students in programs that differ in the depth of presentation of the material, the volume of educational material. 
Our task is to apply a differentiated approach to the organization of distance learning. Let us highlight some features and principles of the distance learning form used by us. Of particular importance is the properly-organized independent work of students. During the period of study at the university, the foundations of professionalism are laid, the skills of independent professional activity are formed. And this connection is especially important for students, mastering the knowledge and methods of obtaining it, to realize that independent work is designed to consolidate the knowledge gained in other types of educational work.

The need to solve the problem of organizing independent work of students in a modern university is connected with the existing contradictions identified in the analysis of the processes occurring in the "system of higher professional education in Russia. On the one hand, the expansion of the information space, the widespread use and emergence of electronic resources and technologies, the increase in its degree of uncontrolled by the teacher led to the need for systemic non-linear changes in the educational process in the university as a whole and the process of organizing students' independent work in particular.

In accordance with the demands of modern information systems, the need for students to possess independent work skills, including using new information technologies, is obvious, on the other hand, the real state of readiness and ability of students to solve professional problems on their own does not meet these needs.

To study this subject, a certain system is needed that facilitates the process of mastering vast material. The most important characteristic of any system is its internal ordering, which in this case is achieved with the help of blocks, since they classify the material under study quite accurately. Here, under the block is understood the internal ordering of the studied material. It remains only to generalize and present these dependencies in the most acceptable for perception and memorization.

All course material is presented in the form of a block-modular system composed of blocks connected in a logical chain according to a certain attribute. Each block, in turn, can branch out, forming other logical chains.

The text is divided into paragraphs that carry certain information, which makes it convenient for initial review.

The main training material is presented in the form of modules with highlighted keywords and definitions, links to other sections of the course, and other sources of information on the Internet, as well as the main conclusions of the section are highlighted. Each module has a title. At the end of the block, a list of issues related to this section is indicated, with sources indicated.

This form of presentation allows you to highlight the main, main and studied section, consider the entire course within a certain system, which can significantly contribute to effective development and provides practical assistance to the student.

\section{Conclusion}

In conclusion, we can say that such structuring ensures the integrity of the perception and presentation of educational material, contributes to a better assimilation of discipline, provides the opportunity to build personal educational trajectories of students.

In our case, when applying a differentiated approach to the organization of distance learning in the form of a block-modular system, we adhere to the following principles: 
- The student has the right to switch from one regime to another during the entire period of study;

- the work on the cycle is considered completed if all the planned tasks are completed and the student has mastered the necessary knowledge, skills;

- he chooses the mode of operation that he considers the most appropriate for himself;

- the student begins to study the educational material in the discipline from the level with which he came after school;

- learns with the speed of assimilation of the material, which is capable of.

- In addition, we apply the principles of a differentiated approach in assessing the knowledge and skills of students.

- For each completed training unit, there are tests on the levels of assimilation, low, medium and high, the implementation of which should show the completeness and depth of assimilation of knowledge.

- This form of organizing the supply of educational material in the form of blocks and the organization of control during distance learning with elements of a differentiated approach will allow you to objectively evaluate your own level of assimilation of the material and make objective conclusions.

So, the advantages of the advantages of this system include:

- flexibility: students work at a convenient time for themselves in a convenient place and at a convenient pace, which is a great advantage for those who study in distance and distance learning forms. Everyone can study as much as he personally needs to master the course (subject, discipline) and obtain the necessary tests for the selected courses (modules);

- individualization of instruction: orientation to any student with different abilities of learning material;

- modularity: each individual section of the course consists of various modules from which the program is formed according to the individual needs of the student;

- differentiated forms of control: the user receives a list of questions according to their level of assimilation, which should reveal the completeness and depth of assimilation of knowledge in this block.

\section{Referencias}

Sakulina, Yu.V. (2018). The use of information and communication technologies in the implementation of distance education. Bulletin of Science and Education, 2 (3 (39)).

Rabunsky, E.S. (1975). An individual approach in the process of teaching students: (Based on the analysis of their independent educational activities). Pedagogy.

Boeva, N.I. (2006). Pedagogical technologies of distance learning.

Professional socialization of students through distance learning: problems, tasks, prospects. World of science, culture, education, (3 (52)).

Galyaev, V.S. \& Gasanova, Z.A. (2012). On the classification of distance learning models. Higher education in Russia, (4).

Celebird, I.N., Lesnaya, N.S., \& Repka, V. B. (2004). Using a multi-agent ontological approach to creating distributed distance learning systems. Educational Technology and Society, 7 (2).

Dubrovskaya, Yu.A. (2005). Pedagogical support of students' self-education in the conditions of distance learning. Diss .... cand. ped sciences / YuA Dubrovskaya. M.

Shevelev, N.A., \& Kuznetsova, T.A. (2011). Organization of the educational environment of the university based on the distance learning system. Higher education in Russia, (7).

Skripkina, Yu.V. (2012). The communicative aspect of creative activity in distance learning. Bulletin of the Institute for Human Education, (2), 22-22. 
Antonova, M. L. (2017). A differentiated approach to teaching English. Education. Career.

Society, (3 (54)). 